\title{
Irving Fisher, Expectational Errors and the UIP Puzzle
}

Rachel Campbell

Maastricht University and RSM Erasmus University

Kees Koedijk

RSM Erasmus University and CEPR

James R. Lothian

Fordham University

Ronald Mahieu

RSM Erasmus University

Follow this and additional works at: https://fordham.bepress.com/crif_seminar_series

Part of the Finance and Financial Management Commons

\section{Recommended Citation}

Campbell, Rachel; Koedijk, Kees; Lothian, James R.; and Mahieu, Ronald, "Irving Fisher, Expectational Errors and the UIP Puzzle" (2007). CRIF Seminar series. 3.

https://fordham.bepress.com/crif_seminar_series/3 
Version 5.5

March 27, 2007

\title{
Irving Fisher, Expectational Errors and the UIP Puzzle
}

\author{
March 2007 \\ Rachel Campbell, Maastricht University and RSM Erasmus University \\ Kees Koedijk, RSM Erasmus University and CEPR \\ James R. Lothian, Fordham University \\ Ronald Mahieu, RSM Erasmus University
}

\begin{abstract}
:
In this paper, we first review Irving Fisher's seminal work on UIP and on the closely related equation linking interest rates and inflation. Like Fisher, we find that the failures of UIP are tied in with individual episodes in which errors surrounding exchange-rate expectations have been persistent but in the end transitory. We find considerable commonality in deviations from UIP and PPP suggesting that both of these deviations are driven by a common factor. Using a dynamic latent factor model we find further that deviations from UIP are almost completely due to forecasting errors in exchange rates - a result consistent with those reported by Fisher a century ago.
\end{abstract}

JEL Classification: F31, B1

Keywords: UIP, Irving Fisher, Expectations formation, small-sample problems

* Campbell: Faculty of Economics and Business Administration, Maastricht University, P.O. Box 616, 6200 MD Maastricht, The Netherlands, tel. 3143 388-4827, email, r.campbell@finance.unimaas.nl.

Koedijk: Department of Financial Management, RSM Erasmus University, Room T9-59, Burgemeester Oudlaan 50, P.O. Box 1738, 3000 DR Rotterdam, The Netherlands, tel. 31104082 748, e-mail, ckoedijk@,rsm.nl. Lothian: Graduate School of Business, Fordham University, 113 West $60^{\text {th }}$ Street, New York, NY 10023, USA, tel., 1212 636-6147, emails, lothian@,fordham.edu ; jrmlothian@aol.com . Mahieu: Department of Financial Management, RSM Erasmus University, Room T9-59, Burgemeester Oudlaan 50, P.O. Box 1738, 3000 DR Rotterdam, The Netherlands, tel. 31104082 295, e-mail, rmahieu@rsm.nl. 


\section{Irving Fisher, Expectational Errors and the UIP Puzzle}

\section{Introduction}

Of the three major international parity relations, uncovered interest rate parity (UIP) has proven the most troublesome empirically. According to UIP, the difference between interest rates in two different currencies will equal the rate of change of the exchange rate between those currencies. Most studies, however, fail to find this positive one-to-one relationship and, indeed, many find a negative relationship. ${ }^{1}$

To Irving Fisher, who arguably was the first to formulate the UIP condition, these anomalous results probably would not have come as a much of a surprise (Dimand, 1999). Fisher viewed UIP as the dual of the interest rate vs. inflation relation or what has come to be called "the Fisher Equation." 2 He saw both as examples of a general relation linking interest rates in different standards.

In discussing this relation, he did so under the heading of "appreciation and interest," first in an monograph with that title published in 1896 by the American Economic Association and later in two books on the subject of interest-rate determination, the Rate of Interest (1907) and his later and more often cited The Theory of Interest (1930). In the case of the Fisher equation, the interest rates in question are, of course, the nominal and real rates of interest and the link between them the expected rate of inflation - the rate at which money depreciates (or appreciates) in terms of goods. In

\footnotetext{
${ }^{1}$ See, for instance, Fama (1984) Hodrick (1987), Bekaert and Hodrick (1993), Bekaert (1995), Dumas and Solnik (1995), Engel (1996), Flood and Rose (1996), Bansal (1997), Bakshi and Naka (1997), Backus, Foresi, and Telmer (2001), Chinn and Meredith (2001), Bekaert, Wei, and Xing (2003), and Brennan and Xia (2005).

2 As Dimand (1999) points out, Fisher was not the first to posit the relationship that now bears his name and was ,moreover, fully aware of that fact, explicitly acknowledging the earlier contributions of among others John Stuart Mill, Alfred Marshall and John Bates Clark, but not Henry Thornton.
} 
the case of UIP, the interest rates are the nominal interest rates of the two countries in question and the link between them is the expected rate of change of the exchange rate the rate at which the one currency is expected to depreciate (or appreciate) in terms of the other.

As is clear from Fisher's discussions of the empirical evidence surrounding the relation between interest and inflation, he saw it as very often subject to violation in the real world. The reason, he claimed, was that people generally did not "adjust at all accurately and promptly" to changes in the behavior of prices but only did so with a long lag (1930, pp.415-416). With regard to UIP he made much the same argument, presenting evidence both of incomplete and delayed adjustment of nominal interest rate differentials to exchange rate movements and of episodes of what now fall under the heading of "peso problems."

In this paper, we first briefly review Fisher's work on this subject. Re-examining the performance of UIP since the advent of floating exchange rates in the 1970s we find the evidence that is largely consistent with Fisher's conjectures.

Like Fisher, we find that the failures of UIP are tied in with individual episodes in which errors surrounding exchange-rate expectations have been persistent but in the end transitory. A first bit of evidence supporting this inference is the increasingly better performance of UIP as the data are averaged over progressively longer periods. A second comes from analysis of UIP in conjunction with the other two key international parity conditions, purchasing power parity (PPP) and real interest rate equality (RIE). Short-tern deviations from UIP and PPP are both substantial and highly correlated, thus pointing to exchange-rate forecast errors, as opposed to risk premia, as the major force driving the 
UIP deviations. We see this in another way when we examine the deviations from RIE, which in principle are independent of exchange-rate forecast errors. These are relatively small in comparison to the deviations from the other two parity conditions and uncorrelated with them. A third body of evidence, derives from a dynamic latent factor model that we use to estimate the magnitudes of the effects of risk premia and exchangerate forecast errors on the UIP relation. For all of the currencies for which we estimate this model, exchange-rate forecast errors again appear to be the principal force behind deviations from UIP. These results, moreover, are robust to alternative model specifications and across countries and time periods.

Fisher's claim made a century ago that "unforeseen monetary changes" are the major cause of departures from UIP and the appreciation-interest relation more generally appear confirmed.

\section{Fisher on UIP and the relation between appreciation and interest}

Fisher's investigation of UIP centered on two bodies of data: yields on U.S. bonds over the period 1870 to 1896 , one bond payable in gold and the other in Greenback currency; and yields on Indian bonds traded in London over the period 1865 to 1894, one bond payable in sterling and the other in silver rupees. ${ }^{3}$

In his analysis of the U.S. data, Fisher focused his discussion on two important episodes: the 1879 resumption of specie payments and the decades surrounding that episode and the 1896 presidential election and three years preceding it. In both he found evidence of behavior consistent with theory. Prior to resumption yields on currency

\footnotetext{
${ }^{3}$ Fisher discusses these results first in his monograph Appreciation and Interest (1896) and then later in his two books on the subject $(1907,1930)$.
} 
bonds exceeded yields on gold bonds as they should have given expectations of an appreciation in the value of the Greenback in terms of gold. At its peak in 1870, the spread between the two stood at 100 basis points. As time passed and the prospects of resumption increased, it narrowed and by mid-1878 had reversed sign. Over the next 15 years the spread between the yields on currency and gold bonds averaged only -37 basis points and in the earlier part of that period generally stood at -20 basis points or less.

Fisher went on to compare the expected rates of appreciation of the Greenback implicit in the yield differentials prior to resumption with realized rates over progressively shorter periods beginning in January 1870 and ending in each instance in January 1879 , the actual date of resumption. The expected rate at the start of this sample was .8 per cent per annum versus a realized rate of 2.1 per cent per annum, a ratio of a bit less than two fifths. Such underestimation was not at all atypical. Not until 1877 did the ratio finally break out of that general range and for a time in 1874 it actually went negative, implying expectations of depreciation rather than appreciation.

If adjustment was incomplete for most of the period prior to resumption, this was certainly not the case in the years leading up to the 1896 presidential election. During that episode, the first of the two peso-problems uncovered by Fisher, to which we alluded above, developed. Yields on currency bonds and gold bonds both increased and the spread between the two progressively widened from 30 basis points in 1893 to a peak of 110 basis points in 1896. Fisher's explanation, which subsequent research has substantiated, attributed these developments to the free-silver agitation and the fears of impending inflation and dollar depreciation that it engendered. "Both the increases and

\footnotetext{
${ }^{4}$ Hallwood, et al. (2000) provide econometric evidence supporting this interpretation. For historical discussions of this episode see Friedman and Schwartz (1963, Chapter 3; 1982, Chapter 7).
} 
the wedging apart of the two rates are explainable as effects of the free-silver proposal and its incorporation (July 1896) in the platform of the democratic [sic] party," Fisher wrote (1930, pp. 402-403).

Fisher conducted a similar analysis using the yield data for India. In the period 1865-1874 when the exchange rate was stable, the yields on gold and silver rupee bonds were almost identical, differing on average by roughly 20 basis points. Then, in 1875 as the rupee began to depreciate, the spreads gradually widened, from an average of close to 40 basis points during the period $1875-1878$, to 64 basis points during the period 1879 1887, to over 100 basis points from 1888 through the first half of 1890 . After further depreciation in the half decade that followed, the exchange rate stabilized at the par value of $£ 16 \mathrm{~d} /$ rupee. As Fisher pointed out, market reactions both to the initial decline and to the eventual stabilization of the rupee, although basically in line with theory, came with substantial lags. In the latter instance, market participants apparently anticipated a further depreciation in the exchange rate that never actually materialized. This is the second of the two peso problems highlighted by Fisher.

In the Theory of Interest, he wrote regarding this incident (p. 407):

"[T]he legal par was reached in 1898 and was maintained thereafter, subject only to the slight variations of exchange due to the cost of shipping specie. But until the par was proved actually stable by two or three years' experience, the public refused to have confidence that gold and the rupee were once more to run parallel. Their lack of confidence was shown in the difference in the rates of interest in gold and rupee securities during the transition period, 1893-1898, and the two or three succeeding years." (emphasis ours)

The rest of Fisher's empirical evidence had to do with the behavior of nominal interest rates within countries, Britain and the United States, in particular, but also France, Germany, India and Japan, and in the Rate of Interest (but not the Theory of 
Interest) also China. This evidence ranged from brief historical descriptions of important episodes, to comparison of the direction of change in nominal interest rates and rates of price change between subperiods of varying lengths and chosen according to whether prices were rising or declining, to comparisons of the standard deviations of nominal interest rates and ex post real interest rates derived from the subperiod data, and later in The Theory of Interest, to computation of simple correlations between contemporaneous values of nominal interest rates and inflation rates and estimation of distributed lag relationships between those two variables.

The comparison of standard deviations is particularly illustrative. The standard deviations of ex post real interest rates were many multiples of the standard deviations of the nominal interest rates in every instance, ratios 4 to 8 times greater in the data analyzed in The Rate of Interest and 7 to 13 times greater in the data analyzed in The Theory of Interest.

Fisher's comparisons of the changes in inflation rates and ex post real interest rates in The Rate of Interest told a similar story. Increases in inflation went hand in glove with decreases in ex post real rates again implying much less than complete adjustment in nominal rates.

Fisher's summation of this evidence is highly illuminating (1907, p. $278 \mathrm{ff}$.):

There are two possible explanations for [this inverse relation]. ... One is that when prices are rising the cause may not be monetary but may lie in a progressive scarcity of commodities produced and exchanged ... The second reason is that these [price] movements are only imperfectly foreseen"

He went on to argue:

Doubtless both of these causes play a part in the explanation in particular cases. Nevertheless there is internal evidence to show that in general the latter factorunforeseen monetary changes - is the more important. This evidence consists in 
the fact that commodity interest fluctuates so widely in some instances becoming negative. (emphasis ours)

He concluded, however, that "When long periods of price movements are taken, the influence of appreciation on interest is more certain, because in averages covering so many years we may be sure that accidental causes are almost wholly eliminated." And he presented evidence for Britain and the United States using averages spanning a decade or more that was entirely consistent with this statement (1907, p. 282-284). The direction of the movements in nominal interest rates and inflation in 7 of the 8 cases is the same and the variability of the ex post real rates is much closer to that of the nominal rates in both countries than in the data for the shorter subperiods.

\section{UIP regressions}

There has been substantial evidence that UIP does not in fact hold, or at least not in the short term. Engel (1996) provides a comprehensive survey of this literature. We also show that empirically UIP does not hold in the short run. We are, however, able to explain why deviations from UIP occur and what is driving these results.

We use monthly data for the period January 1970 to December 2005 for 18 countries relative to the United States: Austria, Belgium, Canada, Denmark, Finland, France, Germany, Greece, Ireland, Italy, Japan, Netherlands, Norway, Portugal, Spain, Sweden, Switzerland and the United Kingdom. The source of most of these data is the International Monetary Fund's International Financial Statistics. Exchange rates are denominated in units of foreign currency per U.S. dollar; interest rates are short-term domestic Treasury bill or money market rates. 


\section{II.A. UIP Regressions}

We begin by running standard UIP regressions of the following form for each country individually over the full sample period:

$$
s_{t+1}-s_{t}=\alpha+\beta\left(i_{t}-i_{t}^{*}\right)+e_{t+1}
$$

where $\mathrm{s}_{\mathrm{t}+1^{-}} \mathrm{s}_{\mathrm{t}}$ is the one-period change in the log spot exchange rate and $\mathrm{i}_{\mathrm{t}^{-}} \mathrm{i}_{\mathrm{t}}$ * is the corresponding foreign vs. U.S. interest differential.

Under the UIP hypothesis, if the return on a domestic $n$-period zero coupon bond is one percentage point per annum higher than that on a foreign bond, one would expect, on average, the foreign currency to appreciate by one percent over the next $n$ periods. A test of the hypothesis $\alpha=0$ and $\beta=1$ in (1), therefore, provides a test of uncovered interest parity.

Most existing studies, however, reject this hypothesis. Indeed, one of the most puzzling feature of exchange-rate behavior since the advent of floating exchange rates in the early 1970 s is the tendency for countries with high interest rates to see their currencies appreciate rather than depreciate as UIP would suggest. This UIP puzzle, known in its other guise as "the forward premium puzzle," is now so well documented that it has taken on the aura of a stylized fact and as a result spawned an extensive second-generation literature attempting to explain it.

The regression results reported in Table 1 are very much in line with other results reported in the literature. In 13 of the 18 countries, the estimates of $\beta$ are zero or negative and in 14 are significantly different from the theoretical value of unity at the five per cent 
level or below. The coefficients of determination in these regressions, in all instances are extremely low and in most instances almost identically zero. In only one case - Spain is the estimate of $\beta$ both positive and significantly different from zero. In short, there is little if any evidence that UIP holds in the monthly data for these countries.

We ran similar regressions using Fisher's data for the United States and India and got very similar results to those reported in Table $1 .^{5}$ In the U.S. case, the estimate of the slope coefficient $\beta$ was positive and in the Indian case negative. In both instances, however, these estimates were both insignificantly different from zero and insignificantly different from unity. It is interesting to see that while Fisher finds sub-periods in which UIP has some validity, the relation still does not hold well in general.

There is, however, somewhat more to the story. As discussed above, Fisher's explanation with regard to the failures of UIP and the appreciation-interest relation more generally centered on small-sample problems and other "accidental" factors affecting that relation. To investigate the possible effects of such influences we run rolling regressions and regressions using pooled data averaged over progressively longer time periods.

\section{B. Rolling regressions}

Plotted in Figure 1 are cross-country averages (the solid line) of the slope coefficients of five-year rolling regressions based on equation (2) estimated for the G7

\footnotetext{
${ }^{5}$ These data were taken from Tables 11 and 12 in Chapter 19 of The Theory of Interest (1930). We report the full results in Table B1 in the appendix
} 
countries plus the Netherlands along with a plus or minus one-standard-deviation range about those averages (the dotted lines) for the period 1975:2 and 2005:12. ${ }^{6}$

What stands out in the chart are the often sizable variations in the slope coefficients over time. We see periods such as the early 1970s and early 1990s in which most of the individual-country coefficients are positive and for a time close to unity. We see them followed, however, by long periods of systematic movements away from this UIP value.

The first such departure began occurred in the 1980s. At the start of the decade we see a gradual decrease in the magnitude of the regression slope coefficients and then large negative values by the end of that decade. This was the period of Reagan-Volcker disinflation, when the Federal Reserve contained and then reversed the process of rising inflation. Expectations with regard to the inflation decline, however, changed more slowly. $^{7}$ During the period thereafter we see a gradual reversion towards unit slope "coefficients in the rolling UIP regressions and hence a return to UIP.

A second major shock was the 1992 ERM crisis when the United Kingdom, followed later by Italy and Spain, pulled out of the European Monetary System in 1992. Here we see a sharp rise in the average slope coefficient. A third major event, one like the 1980s in which we see falling and eventually negative slope estimates, began in the mid to late1990s prior to the introduction of the Euro and appears attributable to the uncertainty that accompanied that episode.

\footnotetext{
${ }^{6}$ We plot the coefficients at the starting points of the sample periods over which the regressions are run. The standard deviations are deviations of the coefficients in the individual-country regression about the average.

${ }^{7}$ See Goodfriend and King (2005) and Lothian and Wu (2005) for discussions of this episode..
} 


\section{II.C. UIP regressions using temporally averaged data}

If the current problems surrounding UIP are in fact episodic phenomena due, as Fisher put it, to "accidental causes," then his solution of averaging the data is appropriate. $^{8}$

We do this in Figure 1 and in the regressions provided in Table 2. Shown in the three panels of Figure 1 are plots of the UIP relation based on five-year, fifteen-year and full-period averages of the data for our 18 countries. Shown along with those data to provide theoretical frame of reference is a 45 degree line drawn through the origin. Listed in Table 2 are the corresponding regression results.

In the five-year averaged data there is a positive but nevertheless quite weak relation between the exchange-rate change and the interest differential. The picture, however, changes markedly as the period over which the data are averaged lengthens. We see this clearly in the bottom two panels of Figure 1. Moving to the fifteen-year averages we find quite a strong positive relationship, and for the full-period averages an even stronger relationship.

The regression results confirm these visual impressions. As the period over which we compute the averages lengthens, the slope coefficients in the regressions increase from less than .02 to .75 , and the standard errors of those regressions decrease from close to 6 percentage points to 1.2 percentage points. Although we can always reject the hypothesis of a unit slope, it is clear from these results that UIP as a long-run first approximation contains a substantial kernel of truth. ${ }^{9}$

\footnotetext{
${ }^{8}$ An alternative is to use very long term data like those used by Lothian and $\mathrm{Wu}(2005)$.

${ }^{9}$ For corroborative evidence, see Lothian and Simaan (1998), Lothian and Wu (2005) and Chinn (2006).
} 
Having looked at the long-run UIP relationship, we now turn to the short-run dynamics of deviations from UIP, first using a three-parity framework and then via estimation of a dynamic latent factor model.

\section{Short-run behavior and the sources of UIP deviations}

In theory, uncovered interest parity is an ex-ante concept, positing equality of expected nominal returns across countries:

$$
i_{t}=i_{t} *+\mathrm{E}_{t}\left[\left(s_{t+1}-s_{t}\right)\right]
$$

Empirical investigations of UIP, however, generally have used actual, ex-post changes in exchange rates as a proxy for their unobservable ex-ante counterparts. Deviations from UIP empirically can, therefore, arise both because of differences between actual and expected exchange-rate changes and to differences in the riskiness of the two assets:

$$
i_{t}-i_{t} *-\left(s_{t+1}-s_{t}\right)=\rho_{t}-\varepsilon_{s t} \text {, }
$$

where $\varepsilon_{s t}$ is the exchange-rate forecast error and $\rho_{t}$ is the ex-ante risk premium:

The risk premium will be positive (or negative) if investors require an expected excess return on a currency to compensate for the risk of holding it. Under the usual assumptions of rational expectations, exchange-rate forecast errors will be random. As

Fisher pointed out, however, there are conditions under which these errors might in fact 
be systematic over time. One situation in which this will occur is if investors anticipate changes in the underlying process generating the return distribution - the "Peso problem" in modern terminology. A second is that of a monetary shock, in the form of a sudden shift in monetary regime. Before investors learn about the true process generating returns, there may be a period in which forecast errors again are systematic over time rather than random. Fisher discussed the first of these two cases in the context of the 1896 U.S. presidential election and the second in the context of the stabilization of the rupee.

\section{A. The three-parity framework}

As a first step in trying to disentangle the effects of risk premia and systematic exchange-rate forecast errors on UIP, we use the framework developed in Marston (1997) and examine the deviations from UIP in conjunction with those from PPP and RIE.

Consider PPP, written here in terms of expected rates of change of the variables:

$$
E_{t}\left[\pi_{t+1}-\pi_{t+1}{ }^{*}\right]=E_{t}\left[\mathrm{~s}_{t+1}-s_{t}\right]
$$

where $\pi$ and $\pi^{*}$ are the rates of inflation in the two countries respectively.

Deviations from PPP can arise either as a result of exchange-rate forecast errors, $\varepsilon_{s t}$, inflation forecast errors, $\varepsilon_{p t}$, or expected changes in the real exchange rate $\theta_{t}$ :

$$
E_{t}\left[\pi_{t+1}-\pi_{t+1} *\right]-E_{t}\left[s_{t+1}-s_{t}\right]=\varepsilon_{s t}+\varepsilon_{p t}+\theta_{t}
$$


Comparing (5) and (3), we see, therefore, that risk premia do not affect PPP deviations while exchange-rate errors affect both UIP and PPP deviations.

UIP, PPP and RIE are not, however, independent. The deviations from any one of these relations is equal to the algebraic sum of the deviations from the other two. Thus, by subtracting (5) from (3), we get an equation for the real-interest differential, $r-r^{*}$, of the form:

$$
r_{t}-r_{t}^{*}=\rho_{t}-\theta_{t}-\varepsilon_{p t},
$$

where $\varepsilon_{p t}$ is an inflation forecast error. The important point to be noticed when we compare (6) with (3) is that UIP deviations and RIE deviations only have risk premia as a common source. Exchange-rate forecast errors do not matter for RIE.

Comparing the time paths of deviations from PPP and RIE with those of from UIP, therefore, allows us to make inferences about the causes of the UIP deviations observed in the data. We do this first in Figure 2 where we use dollar-pound as a representative currency and plot the deviations from the three parity conditions and in Table 2 where we present the correlations between the deviations from the three parity conditions for DM-Euro, British pound sterling and Japanese yen against the dollar.

What immediately strikes the eye in Figure 2 are on the one hand the high correlation between the UIP and PPP deviations and the similar and substantial magnitudes of both, and on the other the low correlation between these deviations and RIE deviations the very much lower magnitude of the latter. In Table 2 we see very the same thing for the other two currencies. 
As shown above, exchange-rate forecast errors are the common factor in the equations (3) and (5) explaining UIP and PPP deviations. They do not, however, appear in equation (6) explaining RIE deviations. That equation and equation (3), in contrast have risk premia as a common factor. The inference that we draw is that exchange-rate forecast errors rather than risk premia are, therefore, major driving force between UIP deviations.

\section{B. A dynamic factor approach to decomposition of the UIP relationship}

To investigate the process driving the UIP deviations, we adopt a dynamic latent factor model as in Harvey (1991). ${ }^{10}$ While this type of model has been extensively used in other fields, univariate models generally have predominated in the exchange-rate literature. $^{11}$

In equations (3), (5) and (6) we wrote the deviations from UIP, PPP and RIE respectively in terms of the risk premium, $\rho_{t}$, exchange rate forecast errors, $\varepsilon_{s t}$, inflation forecast errors, $\varepsilon_{p t}$, and expected changes in the real exchange rate, $\theta_{t}$. Since the last two of these never appear separately in any of the equations, we cannot disentangle their effects. We are, therefore, have a three-equation system with three common factors risk premia, exchange-rate forecast errors, and a factor combining inflation forecast errors and expected changes in the real exchange rate. Each of the three parity conditions

\footnotetext{
${ }^{10}$ Marston (1997) provides this three parity framework, however rather than finding a common factor to the parity condition he provides regression results from regressing deviations from the three parity conditions on a set of conditioning variables.

11 See Wolff (1991) for this approach. Nijman, Palm and Wolff (1993) show that this model is not identified and suggest including information from other time series data, bur are not explicit with regard to which information to include.
} 
is affected by just two of these factors. This, in turn, allows us to distinguish between the effects of risk premia and exchange-rate forecast errors on the UIP relationship.

As such, risk premia only affect nominal and real interest differentials, and not inflation differentials, while systematic errors in forecasting exchange rates only affect nominal and not real interest differentials. We, therefore, have a system of three parity condition equations, with three unknown factors. As a result, by estimating any combination of two parity conditions, we are able to observe the ex-post effects of risk premia and exchange-rate forecast errors on deviations from UIP, and the ex post effects of risk premia and the combination of expected changes in the real exchange rate and inflation forecast errors on deviations from RIE

We model this set of joint parity conditions by estimating a dynamic latent factor model for the unobservable components on the right hand sides of equations (3) and (6). ${ }^{12}$ We estimate and identify the model on the UIP and the RIE parities using the following set of equations in (7), in which the common latent factor, the risk premia, is again denoted by $\rho_{t}$ :

$$
\left(\begin{array}{c}
i_{t}-i_{t}^{*}-\left(s_{t+1}-s_{t}\right) \\
r_{t}-r_{t}^{*}
\end{array}\right)=\left(\begin{array}{c}
c_{U I P} \\
0
\end{array}\right)+\left(\begin{array}{l}
1 \\
1
\end{array}\right) \rho_{t}+\left(\begin{array}{c}
v_{t}^{U I P} \\
v_{t}^{R I E}
\end{array}\right) .
$$

The measurement errors $v_{t}^{U I P}$ and $v_{t}^{R I E}$ are assumed to be iid with a zero correlation and variances $\sigma_{U I P}^{2}$ and $\sigma_{R I E}^{2}$, respectively. The common factor for the risk premium, $\rho_{t}$, is considered to be a latent factor, modeled by an $\mathrm{AR}(1)$ process

\footnotetext{
${ }^{12}$ In Appendix A we provide as a robustness check on these results by using the alternative combinations of UIP and PPP, and PPP and RIE to derive parameter estimates.
} 


$$
\rho_{t}=c_{\rho}+\phi_{\rho} \rho_{t-1}+\eta_{\rho t}, \quad \quad \eta_{\rho t} \sim N\left(0, \sigma_{\rho}^{2}\right)
$$

The model described by equations (7) and (8) is a state space model. For identification reasons we have not included a constant term in the measurement equation for RIE; the constant term in the UIP equation is denoted by $c_{U I P}$. We estimate the model parameters and latent factors by maximum likelihood and compute the likelihood function recursively using the Kalman filter. Once we have determined the common factor, the risk premium, we can identify the exchange-rate forecast error $\varepsilon_{s t}$ and the joint component composed of the inflation forecast error and expected real exchange rate change, $\theta_{t}+\varepsilon_{p t}$, as

$$
\hat{\varepsilon}_{s t}=\left(s_{t+1}-s_{t}\right)-\left(i_{t}-i_{t} *\right)+\hat{\rho}_{t}
$$

and

$$
\hat{\theta}_{t}+\hat{\varepsilon}_{p t}=\hat{\rho}_{t}-\left(r-r_{t}^{*}\right)
$$

where a carat denotes an estimated value.

In Table 4 we present estimation results for the main currencies in our sample, the German deutschmark (subsequently euro), the British pound sterling and the Japanese yen. Similar results were obtained for all other countries in our sample, so we focus on the major currency combinations only. For the GBP we find that the common factor $\rho_{t}$ is non-stationary. The regression coefficients on the lagged risk premium coefficient, $\varphi_{t}$ 
range from 0.941 for the Japanese yen and 0.961 for the pound sterling. ${ }^{13}$ Both of the specific factors are stationary. In Figure 4 we plot the time series of the two latent factor estimates. In comparing the two visually note that the scales for the estimates of the risk premium are much smaller than those for the exchange-rate forecast errors in all three cases. The variance of the risk premium is less than 0.07 in all cases analyzed, whereas the variance of the exchange-rate and the associated forecast errors are roughly ten times larger.

Exchange-rate forecast errors, therefore, clearly appear to play a much more important role in terms of variability than risk premia. The question that we now wish to consider is the relative size of the impacts of the two on UIP deviations. To answer this question we decompose the slope coefficient in the UIP regression (2) in terms of the moments derived in Table (5). We turn to this in the next section.

\section{Expectational Errors and the UIP puzzle}

In the previous section, we used a dynamic latent factor model to disentangle the effects of the risk premia and exchange-rate forecasting errors on deviations from UIP. In this section, we show that it is the forecasting errors, and the subsequent large variance in forecasting exchange rates that account for the large negative estimated slope coefficients normally found in UIP regressions

To see the effect of exchange-rate expectations errors on results of UIP regression results, we first write the estimated slope coefficient for the UIP regression in terms of the standard OLS formula:

\footnotetext{
${ }^{13}$ This is not a problem in this model as the state space model does not require stationarity.
} 


$$
\hat{\beta}=\frac{\operatorname{cov}\left(i_{t}-i_{t}^{*}, s_{t+1}-s_{t}\right)}{\operatorname{var}\left(i_{t}-i_{t} *\right)}
$$

It is clear from (10) that a negative slope coefficient can only occur if $\operatorname{cov}\left(i_{t}-i_{t}{ }^{*}, s_{t+1}-s_{t}\right)$, the covariance between the interest differential and the exchange rate change is negative.

To determine the specific effects of risk premia and exchange-rate expectation errors on the regression coefficient, we use the expression for the deviations from UIP given in equation (3) to get:

$$
\operatorname{cov}\left(i_{t}-i_{t} *-\left(s_{t+1}-s_{t}\right), s_{t+1}-s_{t}\right)=\operatorname{cov}\left(\rho_{t}, s_{t+1}-s_{t}\right)-\operatorname{cov}\left(\varepsilon_{s t}, s_{t+1}-s_{t}\right)
$$

This, in turn, can be rewritten in terms of the covariance of the interest differential and the change in the exchange rate as:

$$
\operatorname{cov}\left(i_{t}-i_{t}^{*}, s_{t+1}-s_{t}\right)=\operatorname{cov}\left(\rho_{t}, s_{t+1}-s_{t}\right)+\operatorname{var}\left(s_{t+1}-s_{t}\right)-\operatorname{cov}\left(\varepsilon_{s t}, s_{t+1}-s_{t}\right)
$$

The result is an expression for the slope coefficient from the UIP regression in terms of both the risk premium and the exchange-rate forecast errors. Since a negative slope in the UIP regression can only occur if $\operatorname{cov}\left(i_{t}-i_{t^{*}}, s_{t+1}-s_{t}\right)$ is negative, then either the covariance of exchange-rate changes with the risk premium has to be negative, or the covariance of exchange rate changes with the exchange-rate forecast error has to be positive and in either instance of sufficient magnitude to outweigh the effects of the other right-hand-side terms in (12). 
Using the results from the dynamic latent factor model, we can estimate the variances and covariances of the various factors and decompose the significance of these two variables on the beta estimates. These moments are shown in Table 5. We find very large positive estimates for the variances and covariances of the variables surrounding exchange-rate expectations errors. The covariance between these errors and exchange rate changes ranges from 8.9 for sterling to 10.3 for the other two currencies; the variance of the exchange rate is of a similar magnitude. Although the covariance of the risk premium with the exchange rate is negative, the empirical estimates for the all three currencies are all small in value with the highest value being -.10 for the sterling.

In the final two rows of Table 5 we report the ratios:

$$
\frac{\operatorname{cov}\left(\rho_{t}, s_{t+1}-s_{t}\right)}{\operatorname{var}\left(i_{t}-i_{t} *\right)}
$$

and

$$
\frac{\operatorname{var}\left(s_{t+1}-s_{t}\right)-\operatorname{cov}\left(\varepsilon_{s t}, s_{t+1}-s_{t}\right)}{\operatorname{var}\left(i_{t}-i_{t} *\right)}
$$

as a percentage of the alternative estimate for the UIP slope coefficient in equation (13)

$$
\frac{\operatorname{cov}\left(\rho_{t}, s_{t+1}-s_{t}\right)+\operatorname{var}\left(s_{t+1}-s_{t}\right)-\operatorname{cov}\left(\varepsilon_{s t}, s_{t+1}-s_{t}\right)}{\operatorname{var}\left(i_{t}-i_{t} *\right)} .
$$

For both sterling and yen, the first component in the numerator of (13) measuring the relative effect of risk premia, on average accounts for $30 \%$ of the size of the estimated betas from the 5 year rolling regressions. Errors in exchange-rate forecasts, in contrast, 
account on average for $70 \%$. For the deutschmark, the contrast between the two effects is even greater - figures of $5 \%$ and $95 \%$ for the risk premium and the exchange-rate forecast error, respectively.

These empirical results, therefore, provide additional support for the Fisherian proposition that the negative slope coefficients very often obtained in UIP regressions depends mainly on errors in exchange-rate expectation and not on time variation in risk premia.

\section{A Fisherian View of Exchange Rates}

The results that we report in this paper concerning UIP are amazingly consistent with those reported a century or more ago by Irving Fisher in his studies of the relationship between appreciation and interest - both in its UIP and interest-vs.-inflation versions. Consistent with Fisher's view, we find evidence of the important role played by episodic phenomena in disturbing that relation. Like Fisher too, we find that the influence of such phenomena dissipates over time.

We conclude that there are long-run deviations from parity conditions that appear to be caused by large, but infrequent, shocks to the monetary environment which systematically affect the error in forecasting the change in exchange rates. ${ }^{14}$ Over the long term, these errors are less important and we find empirical support for UIP. Using the analysis of Marston (1997) we investigate the possibility of a common factor driving

\footnotetext{
${ }^{14}$ Some recent contributions to the literature on explaining the forward discount puzzle include Bacchetta and van Wincoop (2006, incomplete information processing), Sarkissian (2003 incomplete consumption risk sharing).
} 
deviations from parity conditions. We find extremely high correlation coefficients between UIP and PPP deviations that we identify with exchange-arte forecasting errors.

Using a dynamic latent variable model, we are able to estimate the risk-premia and exchange-rate-forecast-error parameters that are driving changes in deviations from UIP. We find evidence of large and persistent forecasting errors. The results support the work of Bacchetta et al. (2007) on the predictability of excess returns on foreign exchange markets due to the predictability of expectational errors. Bacchetta and Wincoop (2005) attribute this predictability to 'rational inattention,' a situation in which investors are rational, but due to significant information costs, are slow in responding to new information. Although we can hypothesize with regard to what may be driving the persistent errors in forecasting exchange rates, we do not attempt to model predictability in excess returns but merely provide strong empirical support that it is indeed expectational errors rather than risk premia that underlie the short-run deviations from UIP. 


\section{Appendix: Robustness analysis}

In this appendix we present evidence on the robustness of the estimated factors from the dynamic latent factor model (7) and (8).

Instead of using the risk premium as our latent variable we could model the exchange-rate forecast error as a latent variable. ${ }^{15}$ In this case, we would combine the deviations from UIP and PPP in the measurement equation to arrive at an alternative model of the form:

$$
\left(\begin{array}{c}
i_{t}-i_{t}^{*}-\left(s_{t+1}-s_{t}\right) \\
\left(\pi_{t+1}-\pi_{t}\right)-\left(\pi_{t+1} *-\pi_{t} *\right)-\left(s_{t+1}-s_{t}\right)
\end{array}\right)=\left(\begin{array}{c}
c_{U I P}^{\prime} \\
0
\end{array}\right)+\left(\begin{array}{c}
-1 \\
-1
\end{array}\right) \varepsilon_{s t}+\left(\begin{array}{c}
v_{t}^{U I P} \\
v_{t}^{P P P}
\end{array}\right)
$$

and

$$
\varepsilon_{s t}=c_{s}+\phi_{s} \varepsilon_{s, t-1}+\eta_{s t}, \quad \eta_{s t} \sim N\left(0, \sigma_{s}^{2}\right),
$$

with errors $v_{t}^{U I P}$ and $v_{t}^{P P P}$ assumed to be independently and identically normally distributed. The parameters and the latent forecast errors $\varepsilon_{s t}$ are again estimated through the Kalman filter. After estimation we can extract the risk premium $\rho_{t}$ and the inflationary components $\theta_{t}+\varepsilon_{p t}$ as follows:

$$
\begin{aligned}
& \hat{\rho}_{t}=i_{t}-i_{t} *-\left(s_{t+1}-s_{t}\right)+\hat{\varepsilon}_{s t}, \\
& \hat{\theta}_{t}+\hat{\varepsilon}_{p t}=\left(\pi_{t+1}-\pi_{t}\right)-\left(\pi_{t+1} *-\pi_{t} *\right)-\left(s_{t+1}-s_{t}\right)+\hat{\varepsilon}_{s t} .
\end{aligned}
$$

\footnotetext{
${ }^{15}$ As a final alternative to specification, we could model the joint risk premium and inflationary forecast term, $\theta_{t}+\varepsilon_{p t}$, as a latent variable. We do not show these results here.
} 
In Table A1 we present the parameter estimates for the bivariate model consisting of both the deviations of UIP and PPP. Note that the latent forecast error has a slightly positive, albeit insignificant, autoregressive coefficient. To compare the estimated series for the forecast errors in the two models, we have computed correlations between the risk premia and forecasts errors computed from the dynamic factor models consisting of equations (7), (8) and equations (A1) and (A2) respectively. In Table A2 we report these results. From the table it can be seen that the time series for risk premia $\rho_{t}$ and the forecast errors $\varepsilon_{s t}$, computed from the two models, are very extremely highly correlated, providing extremely robust results to the model specification. 


\section{References}

Bacchetta, P., Mertens, E., Van Wincoop, E., 2007. Predictability in Financial markets: What Do Survey Expectations Tell Us? Working paper Swiss Finance Institute.

Bacchetta, P., Van Wincoop, E., 2005. Rational Inattention: A Solution to the Forward Discount Puzzle. Working Paper, International Centre for Financial Asset Management and Engineering.

Backus, D., Foresi, S., Mozumdar, A., Wu, L., 2001. Predictable changes in yields and forward rates. Journal of Financial Economics 59, 281-311.

Backus, D., Foresi, S., Telmer, C., 1998. Discrete-time models of bond pricing. Working paper. New York University.

Backus, D., Foresi, S., Telmer, C., 2001. Affine term structure models and the forward premium anomaly. Journal of Finance 56, 279-304.

Baillie, R. T., Bollerslev, T., 2000. The forward premium anomaly is not as bad as you think. Journal of International Money and Finance 19, 471-488.

Bansal, R., 1997. An exploration of the forward premium puzzle in currency markets. Review of Financial Studies 10, 369-403.

Bekaert, G., 1995. The time-variation of expected returns and volatility in foreign exchange markets. Journal of Business and Economic Statistics 13, 397-408.

Bekaert, G., Hodrick, R. J., 2001. Expectation hypotheses tests. Journal of Finance 56, 1357-1394.

Bekaert, G., Hodrick, R. J., Marshall, D. A., 1997. On biases in tests of the exepctations hypothesis of the term structure of interest rates. Journal of Financial Economics 44, 309-348.

Campbell, J., 1995. Some lessons from the yield curve. Journal of Economic Perspectives 9, 129-152.

Chinn, M. D., 2006. The (partial) rehabilitation of interest rate parity in the floating rate era: Longer horizons, alternative expectations, and emerging markets. Journal of International Money and Finance, 25, 7-21.

Chinn, M. D., Meredith, G., 2001. Testing uncovered interest rate parity at short and long horizons during the post-Bretton Woods era, 2005. NBER Working Paper No. 11077. 
Chinn, M. D., Meredith, G., 2004.Monetary policy and long horizon uncovered interest parity, IMF Staff Papers 51, 409-430.

Dimand, Robert W. 1999. Irving Fisher and the Fisher Relation: Setting the Record Straight Canadian Journal of Economics / Revue canadienne d'Economique, 32,744750 .

Engel, C., 1996. The forward discount anomaly and the risk premium: A survey of recent evidence. Journal of Empirical Finance 3, 123-191.

Fama, E., 1984. Forward and spot exchange rates. Journal of Monetary Economics 14, 319-338.

Fisher,Irving. Appreciation and Interest. New York: Macmillan for the American Economic Association, 1896.

Fisher,Irving. The Rate of Interest. New York Macmillan, 1907.

Fisher,Irving. The Theory of Interest, New York and London: Macmillan, 1930.

Flood, R., Rose, A., 2001. Uncovered interest parity in crisis: The interest rate defense in the 1990s. working paper, IMF.

Friedman, M., Schwartz, A. J., 1963. A Monetary History of the United States: 18671960. Princeton University Press, Princeton.

Friedman, M., Schwartz, A. J., 1982. Monetary Trends in the United States and the United Kingdom, their Relation to Income, Prices, and Interest Rates, 1867-1975. University of Chicago Press, Chicago.

Hallwood, P. C., MacDonald, R., Marsh, I. W., 2000. Realignment expectations and the us dollar, 1890-1897: Was there a 'peso problem'?. Journal of Monetary Economics 46, $605-620$.

Harvey, A.C., 1991, Forecasting, Structural Time Series Models and the Kalman Filter. Cambridge University Press.

Lothian, J. R., Simaan, Y., 1998. International financial relations under the current float: Evidence from panel data. Open Economies Review 9, 293-313.

Lothian, J. R., Taylor, M. P., 1996. Real exchange rate behavior: The recent float from the perspective of the past two centuries. Journal of Political Economy 104, 488-509.

Lothian, J.R. and $\mathrm{Wu}, \mathrm{L}$., Uncovered Interest Rate Parity over the Past Two Centuries. Unpublished working paper, Fordham University and Baruch College, June 2005. 
Marston, R. C., 1997. Tests of three parity conditions: Distinguishing risk premia and systematic forecast errors. Journal of International Money and Finance 16, 285-303.

Nijman, Th.E., F.C. Palm, and C.C.P. Wolff, 1993, Premia in Forward Foreign Exchange as Unobserved Components: A Note. Journal of Business and Economic Statistics, 11, pp. 361-365.

Roll, R., 1979, Violations of Purchasing Power Parity and Their Implications for Efficient International Commodity Markets. In International Finance and Trade, eds M.Sarnat and G.P. Szego, 133-176. Ballinger Publishing, Cambridge, MA.

Wolff, C.C.P., 1987, Forward Foreign Exchange Rates, Expected Spot Rates, and Premia: A Signal-Extraction Approach. Journal of Finance, 41, pp. 395-406. 


\section{Table 1: Summary of results of individual-country UIP regressions}

The regressions summarized below were run using monthly data from 1970:2-2005:12 from the International Financial Statistics. For some countries interest rate data are only available at a later starting date. These regressions took the form $\mathrm{s}_{\mathrm{t}+1}-\mathrm{s}_{\mathrm{t}}=\alpha+\beta\left(\mathrm{i}_{\mathrm{t}}-\mathrm{i}_{\mathrm{t}}{ }^{*}\right)$ $+e_{t+1}$, where $s_{t+1}-s_{t}$ is the one-period change in the log foreign vs. U.S. spot exchange rate and $\mathrm{i}_{\mathrm{t}}-\mathrm{i}_{\mathrm{t}} *$ is the corresponding foreign vs. U.S. interest differential.

\begin{tabular}{|c|c|c|c|c|c|c|c|c|c|}
\hline $\begin{array}{l}\text { Full Sample } \\
\text { Regression }\end{array}$ & Intercept & $\begin{array}{l}\text { Standard } \\
\text { Error }\end{array}$ & $\begin{array}{l}t \text { Stat } \\
\alpha=0\end{array}$ & Beta & $\begin{array}{l}\text { Standard } \\
\text { Error } \\
\end{array}$ & $\begin{array}{l}\text { T Stat } \\
B=1\end{array}$ & R Square & $S E E$ & Nobs \\
\hline Austria & -3.327 & 1.931 & -1.723 & -1.135 & 0.705 & -3.029 & 0.006 & 37.449 & 431 \\
\hline Belgium & 0.663 & 2.065 & 0.321 & -1.488 & 0.854 & -2.915 & 0.007 & 37.828 & 431 \\
\hline Canada & 0.846 & 1.065 & 0.794 & -0.463 & 0.480 & -3.048 & 0.002 & 17.616 & 431 \\
\hline Denmark & 0.837 & 2.317 & 0.361 & -0.430 & 0.511 & -2.800 & 0.002 & 37.572 & 408 \\
\hline Finland & -1.440 & 0.176 & -8.173 & 0.002 & 0.005 & -196.260 & 0.000 & 3.657 & 431 \\
\hline France & 1.654 & 2.166 & 0.764 & -0.982 & 0.733 & -2.704 & 0.004 & 37.075 & 431 \\
\hline Germany & -2.678 & 2.214 & -1.209 & -1.431 & 0.854 & -2.847 & 0.008 & 38.528 & 366 \\
\hline Greece & -3.343 & 4.106 & -0.814 & 0.217 & 0.381 & -2.055 & 0.001 & 39.054 & 250 \\
\hline Ireland & -0.929 & 2.576 & -0.361 & 0.559 & 0.501 & -0.881 & 0.004 & 38.459 & 331 \\
\hline Italy & -0.369 & 3.032 & -0.122 & 0.609 & 0.559 & -0.699 & 0.003 & 36.398 & 346 \\
\hline Japan & -2.450 & 0.121 & -20.176 & -0.008 & 0.003 & -316.039 & 0.016 & 2.512 & 431 \\
\hline Netherlands & -1.699 & 0.158 & -10.752 & 0.000 & 0.004 & -241.009 & 0.000 & 3.277 & 431 \\
\hline Norway & -0.508 & 2.136 & -0.238 & 0.139 & 0.493 & -1.747 & 0.000 & 34.511 & 413 \\
\hline Portugal & 4.946 & 1.774 & 2.788 & -0.180 & 0.232 & -5.087 & 0.001 & 36.828 & 431 \\
\hline Spain & 3.024 & 0.395 & 7.657 & 0.262 & 0.093 & -7.939 & 0.048 & 6.325 & 324 \\
\hline Sweden & 0.646 & 1.959 & 0.330 & 0.314 & 0.532 & -1.289 & 0.001 & 35.761 & 431 \\
\hline Switzerland & -6.287 & 2.955 & -2.128 & -1.206 & 0.604 & -3.654 & 0.011 & 42.088 & 364 \\
\hline UK & 5.557 & 2.541 & 2.187 & -1.930 & 0.783 & -3.741 & 0.014 & 35.270 & 431 \\
\hline
\end{tabular}




\section{Table 2: Results of UIP regressions for non-overlapping averages of the data}

The regressions summarized below are pooled regressions run using the averaged data. For some countries, there are missing observations since some series have later starting dates. The countries analyzed are: Austria, Belgium, Canada, Denmark, Finland, France, Germany, Greece, Ireland, Italy, Japan, Netherlands, Norway, Portugal, Spain, Sweden, Switzerland and the UK, all versus the US.

\begin{tabular}{clllllllll} 
Average & Intercept & $\begin{array}{l}\text { Standard } \\
\text { Error }\end{array}$ & $\begin{array}{l}\boldsymbol{t} \text { Stat } \\
\boldsymbol{\alpha}=\mathbf{0}\end{array}$ & Beta & $\begin{array}{l}\text { Standard } \\
\text { Error }\end{array}$ & $\begin{array}{l}\boldsymbol{t} \text { Stat } \\
\boldsymbol{\beta}=\mathbf{1}\end{array}$ & R Square & $\boldsymbol{S E E}$ & Nobs \\
\hline 5-year & -0.088 & 0.631 & -0.140 & 0.259 & 0.168 & -4.413 & 0.023 & 5.864 & 102 \\
15-year & -0.457 & 0.314 & -1.452 & 0.667 & 0.097 & -3.428 & 0.612 & 1.576 & 32 \\
35-year & -0.729 & 0.349 & -2.089 & 0.758 & 0.110 & -2.207 & 0.749 & 1.245 & 18 \\
\hline
\end{tabular}


Table 3: Correlation of deviations from ex-post UIP, PPP and RIE

\begin{tabular}{llll} 
Full sample & UIP \& PPP & UIP \& RIE & PPP \& RIE \\
& & & \\
Germany & 0.994 & 0.034 & 0.110 \\
Japan & 0.981 & 0.030 & 0.171 \\
UK & 0.981 & -0.020 & 0.153 \\
\hline
\end{tabular}


Table 4: Estimation results for the dynamic factor model (7) and (8)

Parameter estimates for the dynamic factor model consisting of equations (7) and (8) in the text. The currencies included are deutschemark/euro (DEM), British pound sterling (GBP), and Japanese yen (JPY), all versus the U.S. dollar. The estimation period is from January 1976 to December 2005.

\begin{tabular}{|l|l|l|l|}
\hline & DEM & GBP & JPY \\
\hline $\mathrm{c}_{\text {UIP }}$ & -0.019 & 0.096 & 0.148 \\
& $(0.145)$ & $(0.143)$ & $(0.158)$ \\
$c_{\rho}$ & 0.003 & 0.002 & -0.006 \\
& $(0.003)$ & $(0.003)$ & $(0.003)$ \\
$\phi_{\rho}$ & 0.943 & 0.961 & 0.941 \\
& $(0.018)$ & $(0.002)$ & $(0.016)$ \\
$\sigma_{\rho}$ & 0.050 & 0.073 & 0.069 \\
& $(0.002)$ & $(0.002)$ & $(0.002)$ \\
$\sigma_{U I P}$ & 3.209 & 3.008 & 3.303 \\
& $(0.000)$ & $(0.000)$ & $(0.000)$ \\
$\sigma_{R I E}$ & 0.024 & 0.018 & 0.012 \\
& $(0.000)$ & $(0.000)$ & $(0.000)$ \\
\hline
\end{tabular}




\section{Table 5: Moments}

The currencies included are deutschemark/euro (DEM), British pound sterling (GBP), and Japanese yen (JPY), all versus the U.S. dollar. The estimation period is from January 1976 to December 2005. The "OLS beta" coefficient is calculated from the UIP regression (1) over the sample period January 1976 to December 2005. The "Implied beta" is calculated from equation (13).

\begin{tabular}{|c|c|c|c|}
\hline & DEM & GBP & JPY \\
\hline $\operatorname{var}\left(\rho_{t}\right)$ & 0.0221 & 0.0669 & 0.0417 \\
\hline $\operatorname{var}\left(s_{t+1}-s_{t}\right)$ & 10.348 & 8.9698 & 10.272 \\
\hline $\operatorname{var}\left(i_{t}-i_{t} *\right)$ & 0.0395 & 0.0328 & 0.0448 \\
\hline $\operatorname{cov}\left(i_{t}-i_{t}^{*}, s_{t+1}-s_{t}\right)$ & -0.0477 & -0.0651 & -0.0882 \\
\hline $\operatorname{var}\left(\varepsilon_{s t}\right)$ & 10.387 & 8.9736 & 10.382 \\
\hline $\operatorname{cov}\left(\rho_{t}, s_{t+1}-s_{t}\right)$ & -0.0438 & -0.1005 & -0.0710 \\
\hline $\operatorname{cov}\left(\varepsilon_{s t}, s_{t+1}-s_{t}\right)$ & 10.323 & 8.9130 & 10.290 \\
\hline OLS beta & -1.204 & -1.943 & -1.805 \\
\hline Implied beta & -2.097 & -3.164 & -3.435 \\
\hline $\begin{array}{l}\text { Variaton due to } \\
\operatorname{cov}\left(\rho_{t}, s_{t+1}-s_{t}\right) \\
\text { Variaton due to } \\
\operatorname{var}\left(s_{t+1}-s_{t}\right)- \\
\operatorname{cov}\left(\varepsilon_{s t}, s_{t+1}-s_{t}\right)\end{array}$ & $4.76 \%$ & $\begin{array}{l}29.48 \% \\
70.52 \%\end{array}$ & $\begin{array}{l}29.86 \% \\
70.14 \%\end{array}$ \\
\hline
\end{tabular}


Table A1: Estimation results for the dynamic factor model using deviations from UIP and PPP

Parameter estimates for the dynamic factor model consisting of equations (A1) and (A2) in the text. The currencies included are deutschemark/euro (DEM), British pound sterling (GBP), and Japanese yen (JPY). All exchange rates are against the US dollar. The estimation period is from January 1976 to December 2005.

\begin{tabular}{|l|l|l|l|}
\hline & DEM & GBP & JPY \\
\hline $\mathrm{c}_{\text {UIP }}$ & 0.053 & 0.034 & -0.089 \\
& $(0.008)$ & $(0.013)$ & $(0.010)$ \\
$c_{s}$ & 0.024 & -0.081 & -0.134 \\
& $(0.163)$ & $(0.147)$ & $(0.111)$ \\
$\phi_{s}$ & 0.041 & 0.081 & 0.090 \\
& $(0.034)$ & $(0.053)$ & $(0.047)$ \\
$\sigma_{s}$ & 3.228 & 2.983 & 3.214 \\
& $(0.105)$ & $(0.103)$ & $(0.102)$ \\
$\sigma_{U I P}$ & 0.022 & 0.258 & 0.207 \\
& $(0.014)$ & $(0.004)$ & $(0.001)$ \\
$\sigma_{P P P}$ & 0.150 & 0.002 & 0.012 \\
& $(0.007)$ & $(0.012)$ & $(0.002)$ \\
\hline
\end{tabular}


Table A2: Correlations between estimated risk premia and forecast errors

Correlations between time series for risk premia $\rho_{t}$ and forecast errors estimates $\varepsilon_{s t}$, both computed for the dynamic factor models consisting of equations (7) and (8), and equations (A1) and (A2), respectively. The currencies included are deutschemark/euro (DEM), British pound sterling (GBP), and Japanese yen (JPY). All exchange rates are against the US dollar. The estimation period is from January 1976 to December 2005.

\begin{tabular}{|l|l|l|l|}
\hline & DEM & GBP & JPY \\
\hline Risk premia $\rho_{t}$ & 0.958 & 0.975 & 0.969 \\
Forecast errors $\varepsilon_{s t}$ & 0.999 & 0.999 & 0.999 \\
\hline
\end{tabular}


Table B1: Results of UIP regressions based on Irving Fisher's data for U.S. gold and greenback bonds and Indian sterling and rupee bonds

The regressions summarized below use the data reported in Tables 11 and 12 of The Theory of Interest (1930.

\begin{tabular}{|c|c|c|c|c|c|c|c|c|}
\hline Ave & Intercept & $\begin{array}{l}\text { Standard } \\
\text { Error }\end{array}$ & $\begin{array}{l}t \text { Stat } \\
\alpha=0\end{array}$ & Beta & $\begin{array}{l}\text { Standard } \\
\text { Error }\end{array}$ & $\begin{array}{l}t \text { Stat } \\
\beta=1\end{array}$ & R Square & $S E E$ \\
\hline U.S. Bonds & -1.037 & 0.724 & -1.433 & 2.608 & 1.434 & 1.122 & 0.091 & 4.283 \\
\hline Indian Bonds & -0.020 & 1.369 & -0.014 & -2.012 & 2.435 & -1.237 & 0.019 & 4.312 \\
\hline
\end{tabular}


Figure 1: Averages of coefficients from 5-year rolling regressions for the G7 countries and one-standard deviation bounds

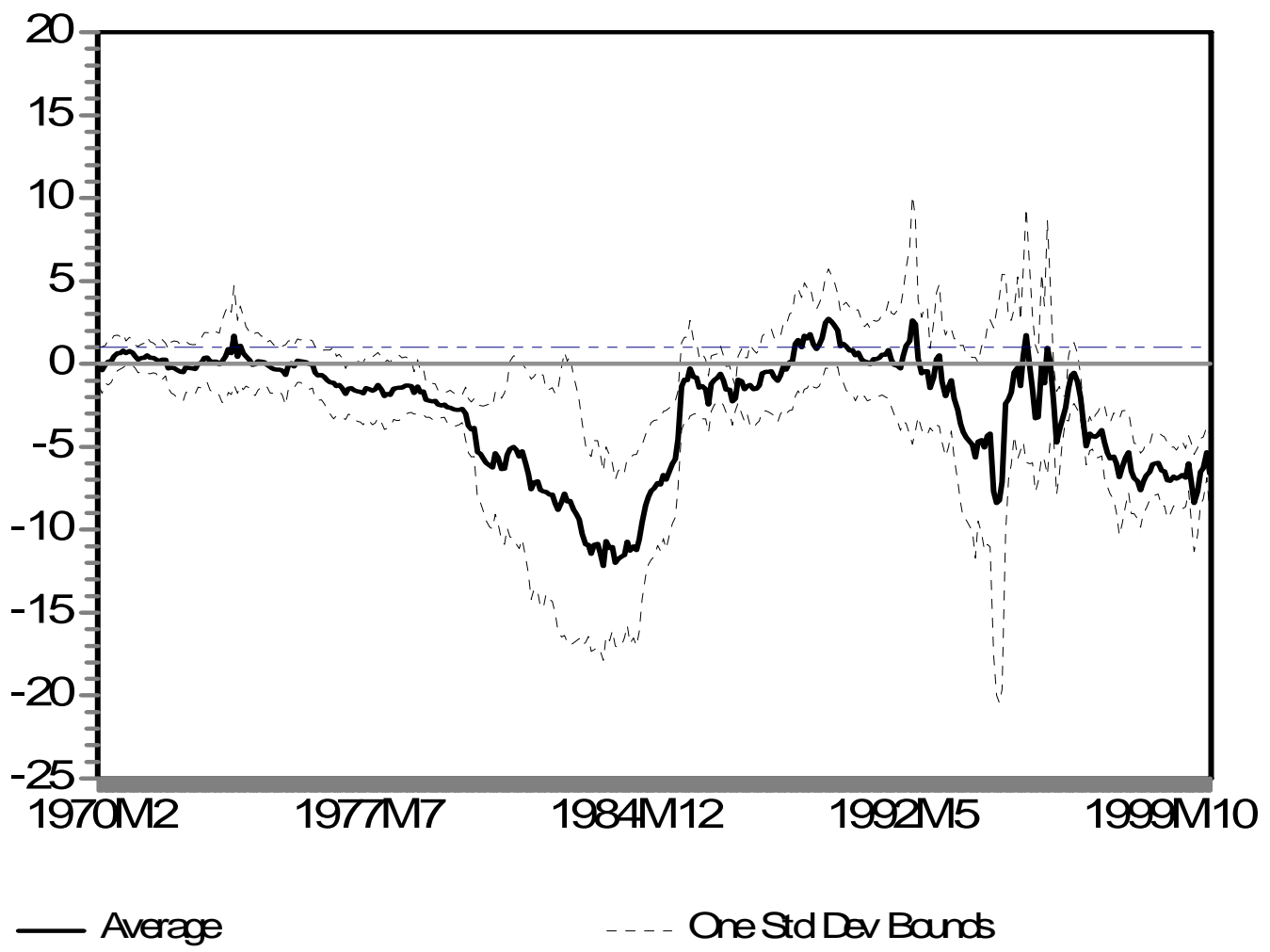




\section{Figure 2: UIP relations based on 5-year, 15-year and full-period averages}

Plotted in the charts are data for all 18 countries. For Spain and Portugal these data begin in 1985. The 5-year sample periods were 1970-1975, 1975-1980, 1985-1990, 1990-1995, 1995-2000, 2000-2005; the . 15 year sample periods were 1975-1990 and 1990-2005.

Five-year Averages

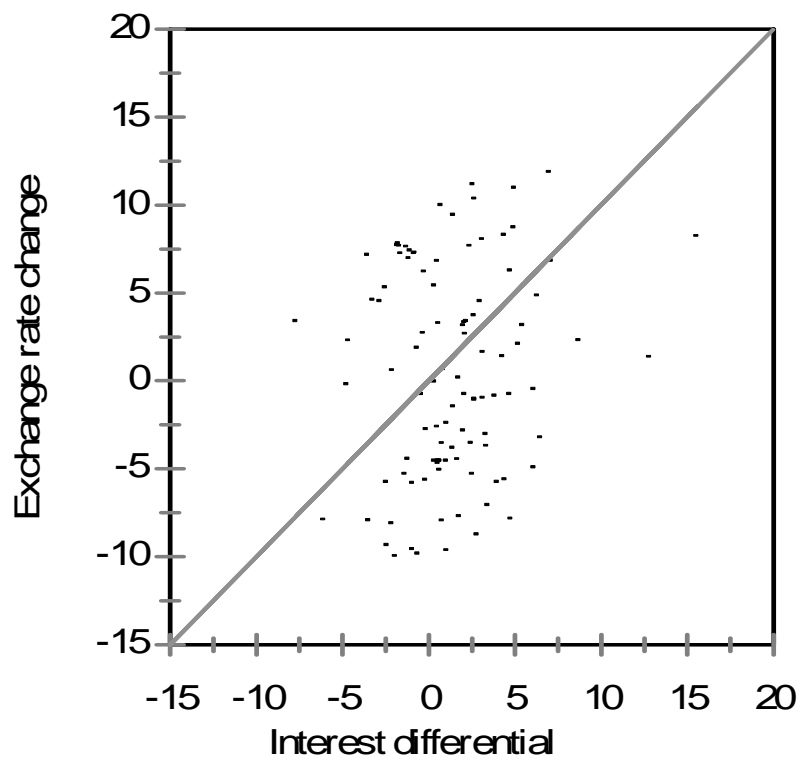

Fifteen-year Averages

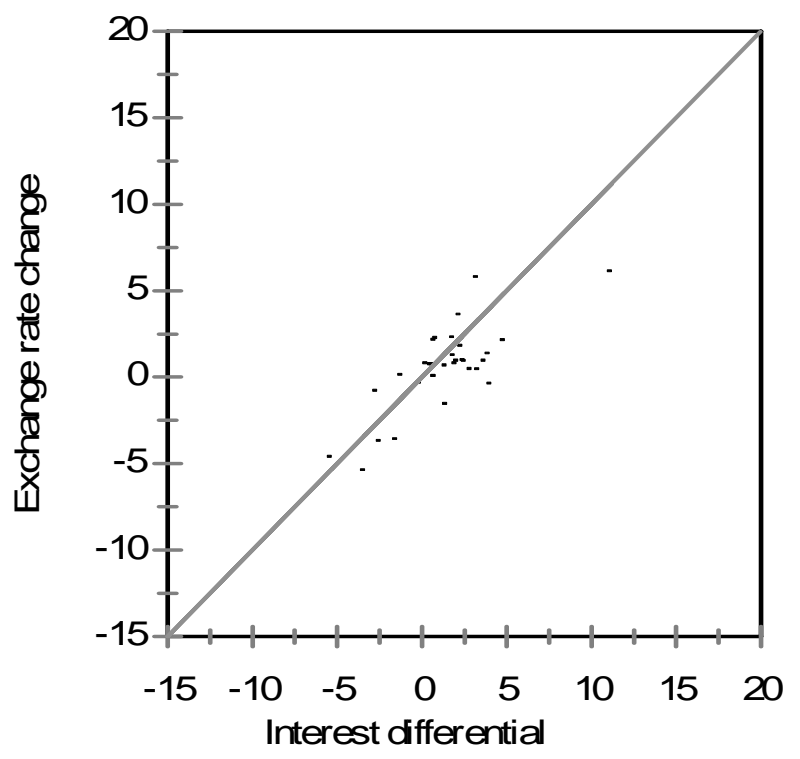


Full-period Averages

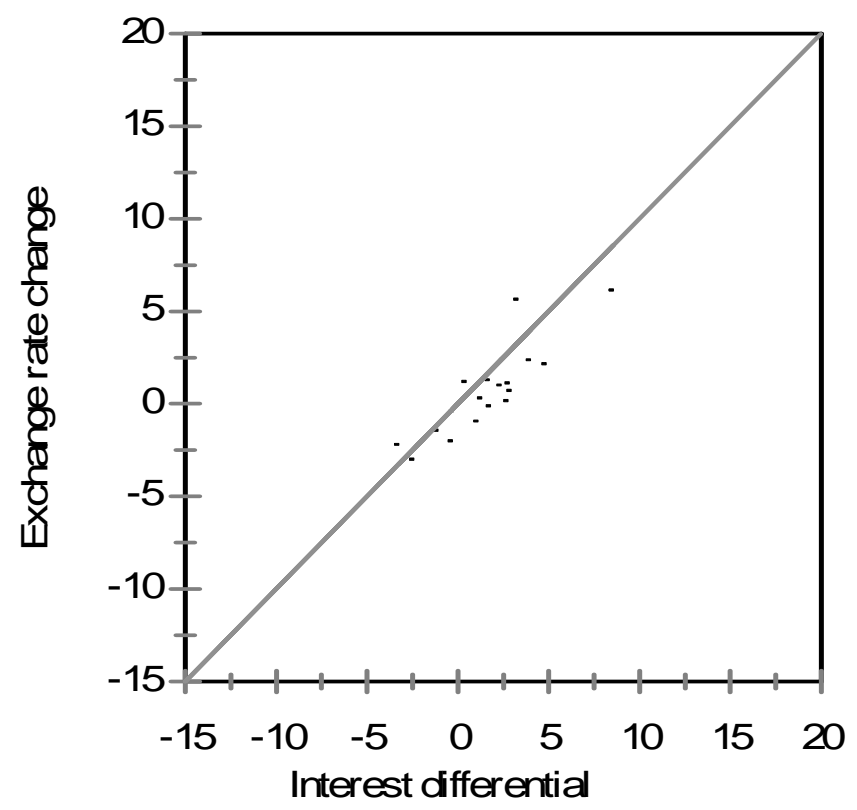


Figure 3: Ex-Post Deviations from UIP and PPP parity conditions for the US and the UK from January 1970 - December 2005.

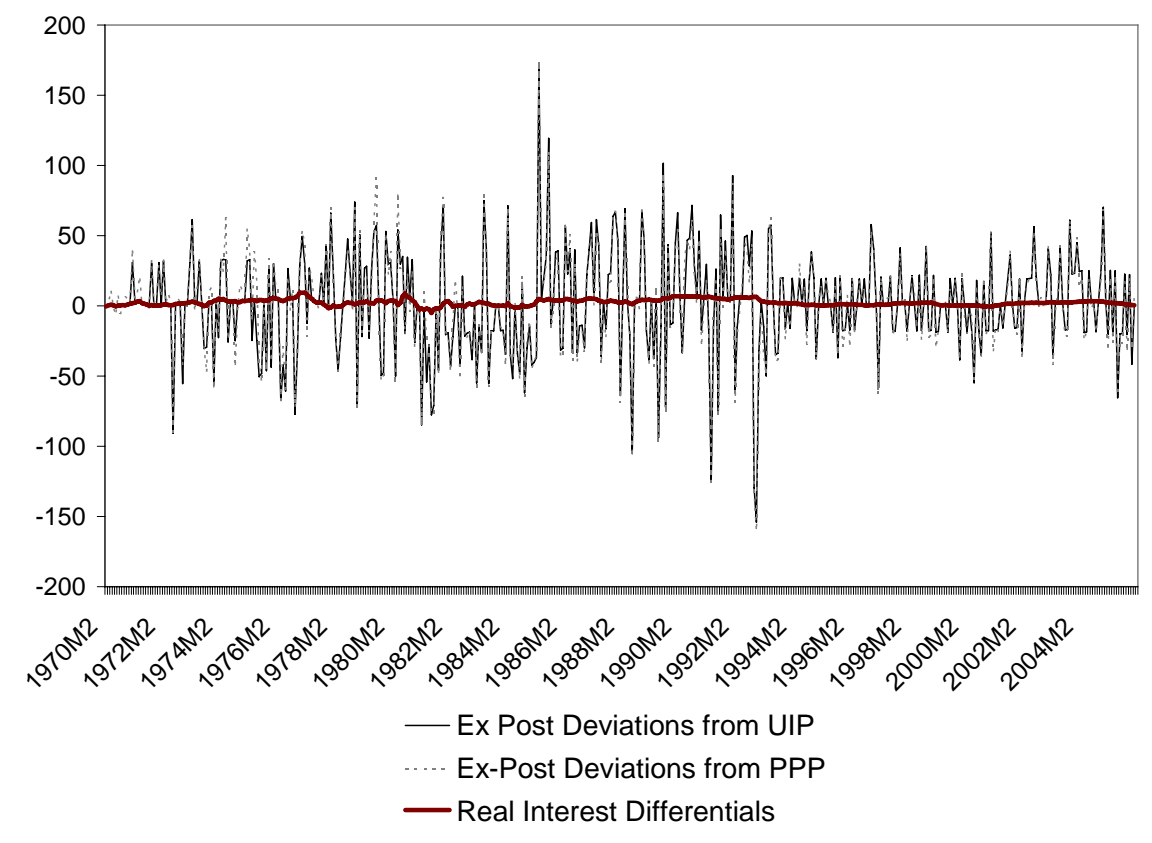


Figure 4: Estimated factors from the dynamic factor model (7) and (8)

\section{DEM / Euro}

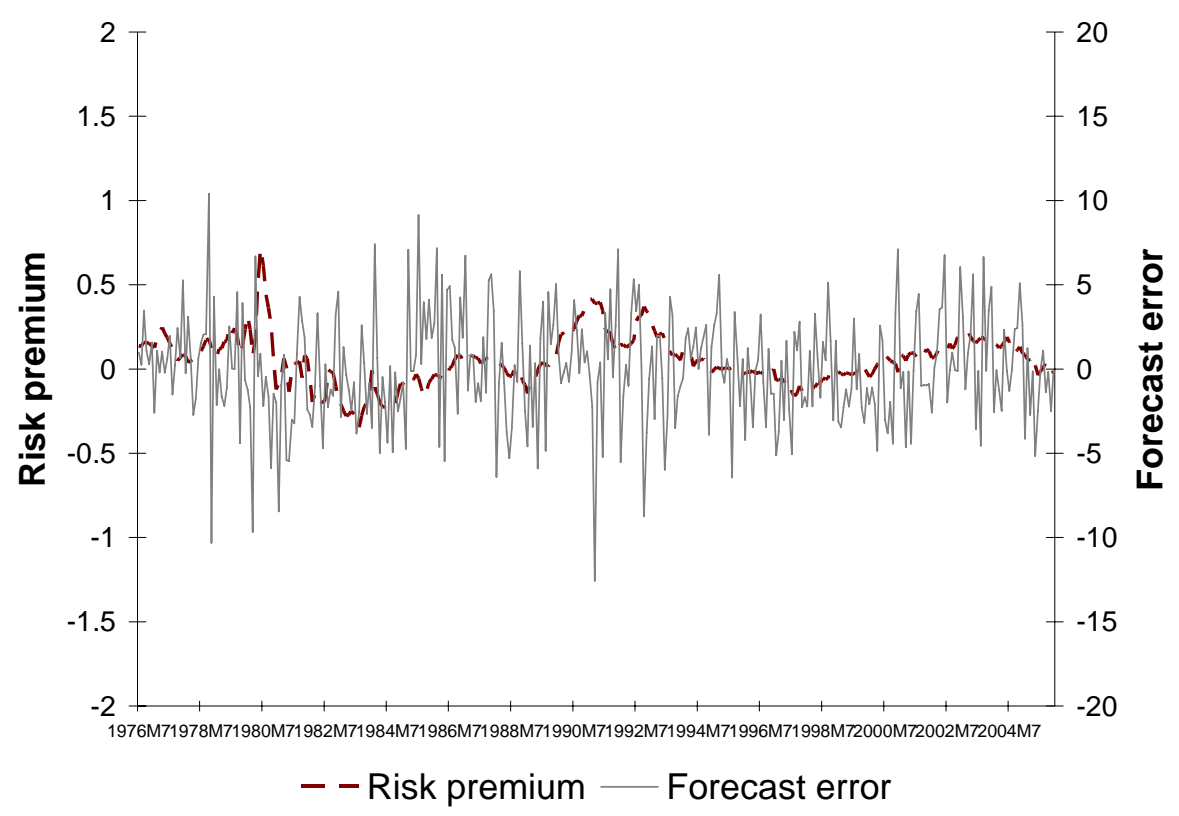

GBP:

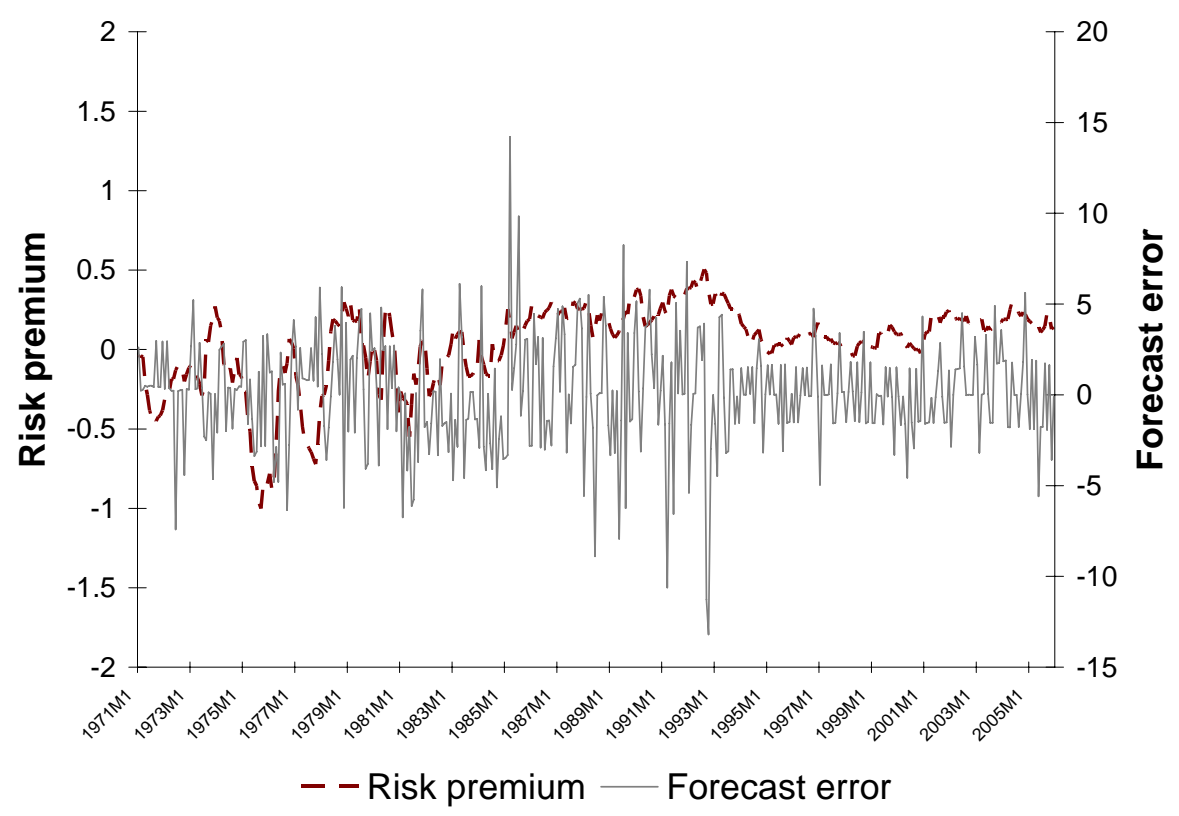




\section{JPY:}

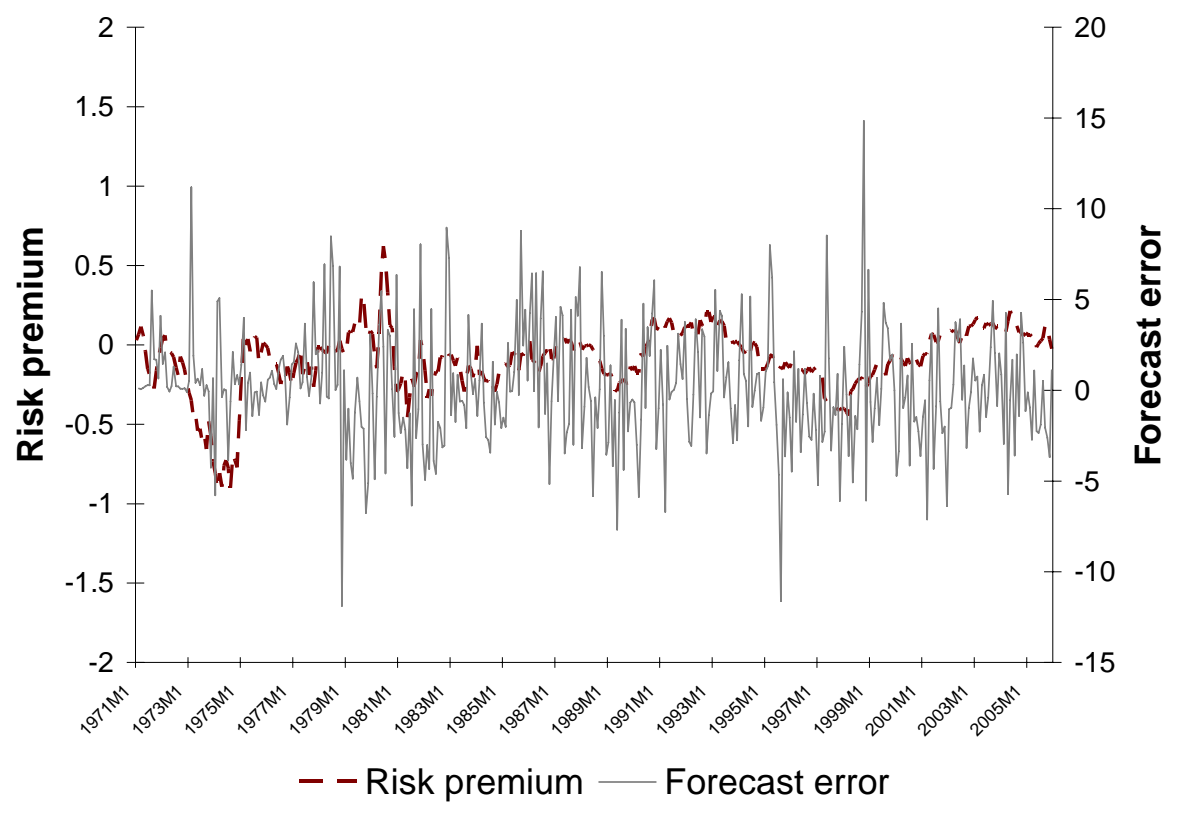

